\title{
Environmental tritium contamination from a gaseous tritium light device maintenance facility
}

\author{
R. Kleinschmidt, S. Barr, M.L. Cook and D. Watson \\ Health Physics Unit, Queensland Health Forensic and Scientific Services, PO Box 594, \\ Archerfield, 4108 Queensland, Australia
}

\begin{abstract}
An investigation was undertaken in relation to the contamination of a facility used for the servicing and refurbishment of gaseous tritium light devices. While it is generally accepted that there is minimal exposure hazard from a broken gaseous tritium light source after the tritium gas has dispersed, environmental tritium contamination displaying 'particulate' like characteristics was observed during the radiological assessment of the facility in 2003 . The contamination is considered to be associated with zinc sulphide phosphor residues from damaged tritium light sources. A subsequent environmental tritium survey was conducted in 2007, in the vicinity of the affected building to determine the extent of contamination and impact on current and future occupancy and land use application. The survey was conducted by measuring both soil non-aqueous tritium and soil pore water tritium concentration. Zinc concentration, from the zinc sulphide phosphor, was also measured for the same samples to assess correlation between tritium contamination activity and the identified source material. Greater than $97 \%$ of the soil non-aqueous tritium results were observed to be less than the derived tritium residential screening level of $8.5 \mathrm{~Bq} \cdot \mathrm{kg}^{-1}$, and that soil pore water tritium concentrations had decreased from $8 \mathrm{MBq} \cdot \mathrm{L}^{-1}$ to less than $2 \mathrm{kBq} \cdot \mathrm{L}^{-1}$ over a period of 5 years. Elevated elemental zinc levels in the upper surface soils correlated with increased non-aqueous tritium concentration. Ground water tritium concentrations ranged from $3 \mathrm{~Bq} \cdot \mathrm{L}^{-1}$ to $20 \mathrm{~Bq} \cdot \mathrm{L}^{-1}$, indicating leakage of tritium contaminated water to local aquifer systems. Natural attenuation and dilution processes have reduced environmental tritium contamination levels over a period of 5 years since the introduction of new contamination control policies and operational changes at the facility.
\end{abstract}

\section{INTRODUCTION}

A series of radiological characterisation, decontamination works and validation assessments have been conducted for a Gaseous Tritium Light Device (GTLD) maintenance facility in Brisbane, Australia in 2003 and more recently in 2007. Environmental tritium contamination (via soil pore water determinations) was observed in the immediate areas surrounding the facility.

The facility was used for the maintenance of military optical instruments and cold light sources. A number of these instruments incorporated Gaseous Tritium Light Sources (GTLS) in their construction. While it is generally accepted that there is minimal exposure hazard from a broken GTLS after the tritium gas has dispersed, the contamination in this case is considered to be associated with the zinc sulphide phosphor residues from damaged light sources, and exhibits contamination patterns similar to particulate material. Residues derived from damaged GTLS components have been deposited outside the confines of the facility by a number of processes including; contamination of worker clothing and subsequent deposition, expulsion via air handling equipment (air conditioning unit and radioactive waste store unfiltered ventilation system), and most predominantly, general cleaning activities. It is considered that the majority of contamination is a result of accumulation of particulate material on floors, subsequent washing during routine cleaning, and disposal of wash water at egress points around the facility (Figure 1).

An initial survey utilised soil pore water tritium concentration as an indicator of the extent of contamination. Tritium, existing as tritiated water or HTO, is environmentally mobile and tends to behave as non-radioactive water would, i.e. will permeate through soil under normal hydraulic 


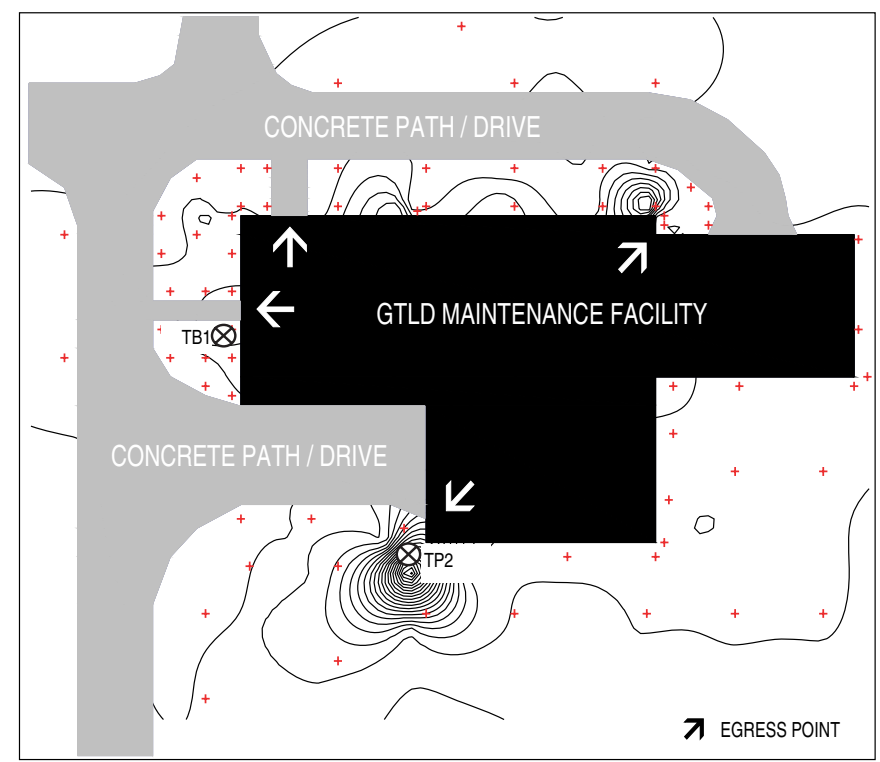

Figure 1. Soil nHTO concentration contour map showing correction with egress point from the facility.

conditions. A more useful measure for the purposes of dealing with contaminated land is the 'nonaqueous tritium' (nHTO) concentration present in the soil. In addition to tritium existing as HTO, organically bound tritium, a result of fixation by biological and chemical processes, or tritium diffused into various matrices may be present and represent the non-aqueous component. Quantification of all these variants allows assessment of the reservoir of tritium that may become available in environmental processes. NCRP [1] screening soil contamination levels for non-aqueous tritium concentration of $8.5 \mathrm{~Bq} \cdot \mathrm{g}^{-1}$ and $16 \mathrm{~Bq} \cdot \mathrm{g}^{-1}$ for residential and industrial/commercial land uses respectively, were applied.

\section{MATERIALS AND METHODS}

\subsection{Sampling}

The sampling design was developed to establish the extent of contamination in the immediate vicinity of the facility and surrounding areas using a combination of systematic and judgement based analyses of the site, the nature of the contaminants and site operational processes. Initial environmental sampling and analysis results for the site suggest that the contaminant source will be maintained in the upper soil profiles, with the potential for tritiated water derived from oxidation of tritium migrating or leaching from the contaminated zinc sulphide, permeating down through the soil profile in conjunction with precipitation or irrigation waters.

Surface soil samples were collected (separating vegetation) to a depth of $100 \mathrm{~mm}$. A test bore (TB1) and test pit (TP2) were installed using a hand auger to allow for $100 \mathrm{~mm}$ incremental sub-surface soil sampling to a depth of around $1200 \mathrm{~mm}$. Samples collected using these methods were used for nHTO \& soil pore HTO analysis, and elemental zinc determination as required. Two groundwater monitoring wells were installed and were used in conjunction with three existing wells for sampling. Sampling was conducted on two occasions over 3 weeks to assess potential groundwater contamination. Groundwater samples were collected using a stainless steel bailer. 


\subsection{Analysis}

The tritium contamination has been shown to be associated with zinc sulphide from damaged GTLS components as the primary contaminant, and subsequently metabolised or integrated into organic material found in soils. Quantification of the nHTO inventory in the soil requires extraction techniques that will release all tritium present. The extraction method used was based on that described by Castellano and Dick [2]. Using $10 \mathrm{~g}$ of soil and $50 \mathrm{~mL}$ of extraction fluid with subsequent distillation, a $1 \mathrm{~mL}$ aliquot of extracted fluid, counted for 60 minutes, yields a nHTO tritium minimum detection level of $0.050 \mathrm{~Bq} \cdot \mathrm{g}^{-1}$. Soil pore HTO concentration was determined by removal of pore water by evaporation and distillation. The method is based on that described by Gudelis et al. [3]. Using $100 \mathrm{~g}$ of soil, a $1 \mathrm{~mL}$ aliquot of evaporated and distilled fluid, with a count time of 180 minutes, yields a soil pore HTO minimum detection level of $15 \mathrm{~Bq} \cdot \mathrm{L}^{-1}$. A Perkin Elmer QUANTULUS $1220^{\mathrm{TM}}$ liquid scintillation spectrometer was used for nHTO and soil pore HTO determinations. Groundwater samples were prepared and analysed using the method described in ISO 9698. Analysis was conducted using a Packard $3170 \mathrm{TR} / \mathrm{SL}^{\mathrm{TM}}$ ultra low level liquid scintillation analyser. Using an $8 \mathrm{~mL}$ aliquot of distilled sample, with a count time of 240 minutes, yields a tritium minimum detection level of $3 \mathrm{~Bq} \cdot \mathrm{L}^{-1}$.

To confirm the assumption that 'tritiated' zinc sulphide is the primary environmental contamination vector, elemental zinc analysis was conducted on soil samples collected from TP 2 to evaluate correlation with nHTO concentration. Zinc contamination was extracted using a 48 hour, $0.5 \mathrm{M}$ nitric acid digest followed by analysis by ICPAES.

\section{RESULTS AND CONCLUSIONS}

Greater than $97 \%$ of nHTO soil tritium concentration levels (range of $0.05 \mathrm{~Bq} \cdot \mathrm{g}^{-1}$ to $21 \mathrm{~Bq} \cdot \mathrm{g}^{-1}$ ) were less than the residential screening level of $8.5 \mathrm{~Bq} \cdot \mathrm{g}^{-1}$. Soil nHTO and soil pore HTO concentration was compared in incremental depth samples collected from test bore/pits (Figure 2a). The results confirm that a reservoir of tritium is present in the upper $100 \mathrm{~mm}$ soil layer, and that tritiated pore water is mobile within the soil column, concentration increasing with depth until pooling over an impermeable clay horizon at approx. $1 \mathrm{~m}$ depth. Leakage of accumulated, contaminated water from this horizon (i.e. through construction penetrations in the impermeable layer) is considered as the transport mechanism to local aquifers. Comparison of surface pore water concentration from this study with that in 2003 indicates that the pore water concentration has decreased from $8 \mathrm{MBq} \cdot \mathrm{L}^{-1}$ to less than $2 \mathrm{kBq} \cdot \mathrm{L}^{-1}$ over a period of 5 years. Soil zinc concentration is compared with nHTO concentration in Figure $2 \mathrm{~b}$. Zinc distribution within the soil $\log$ correlates with nHTO concentration, confirming the hypothesis that tritium concentration is directly related to zinc associated with phosphor material. Elevated zinc levels within the upper horizons further confirm that zinc sulphide was the deposition mechanism for the tritium contamination, and that this material remains resident in the upper horizons with little mobility to lower horizons (other than bioturbation and surface soil mixing processes). Groundwater monitoring

Table 1. Tritium concentration in groundwater monitoring wells surrounding the facility.

\begin{tabular}{|c|c|c|c|}
\hline Well & Date & $\begin{array}{c}\text { Max. } \\
\text { Location Relative to } \\
\text { Facility }\end{array}$ & $\begin{array}{c}\text { (ancentration } \\
\left(\mathbf{B q} \cdot \mathbf{L}^{-\mathbf{1}}\right)\end{array}$ \\
\hline ETMW01 & 05 Sept 2007 \& 27 Sept 2007 & $20 \mathrm{~m} \mathrm{SW}$ & $3 \pm 3$ \\
BMW09 & 05 Sept 2007 \& 27 Sept 2007 & $20 \mathrm{~m} \mathrm{SE}$ & $23 \pm 3$ \\
BMW04 & 05 Sept 2007 \& 27 Sept 2007 & $24 \mathrm{~m} \mathrm{NW}$ & $5 \pm 3$ \\
ETMW02 & 05 Sept 2007 \& 27 Sept 2007 & $12 \mathrm{~m} \mathrm{~N}$ & $10 \pm 2$ \\
BMW08 & 05 Sept 2007 \& 27 Sept 2007 & $30 \mathrm{~m} \mathrm{NE}$ & $3 \pm 3$ \\
\hline
\end{tabular}



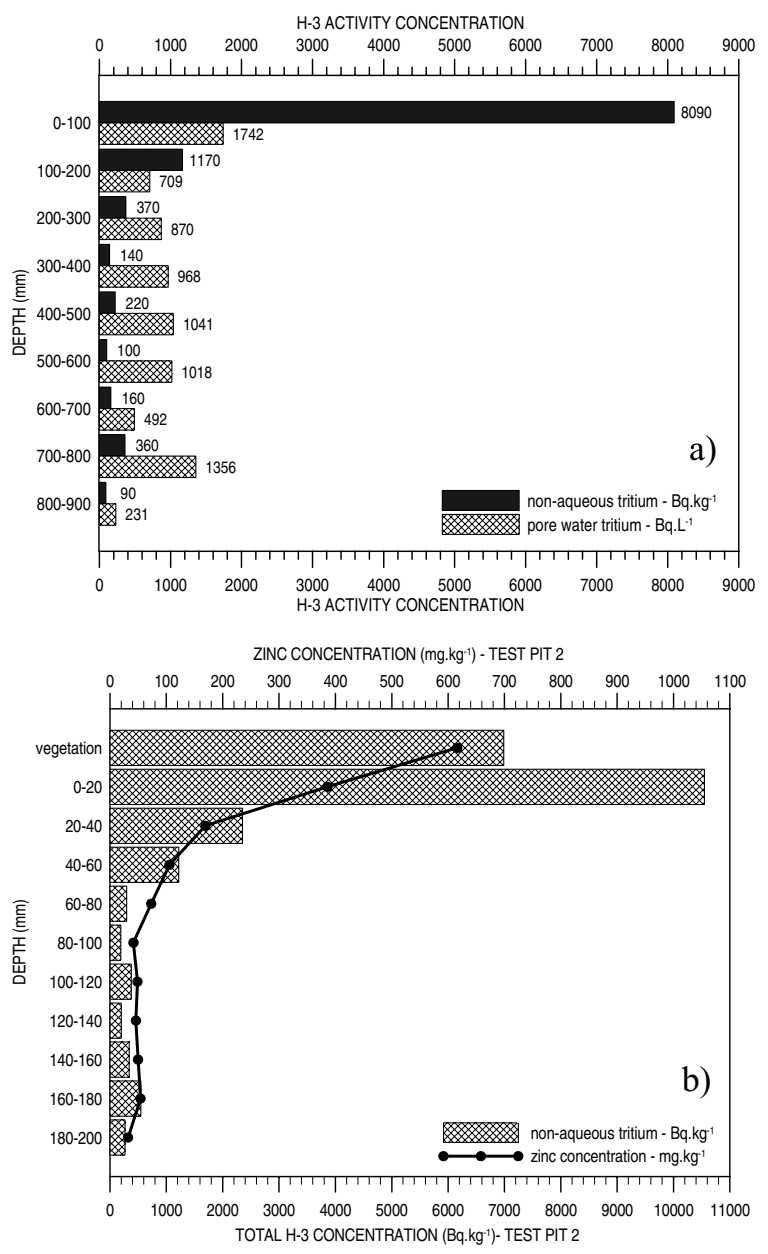

Figure 2. a) Comparison of soil nHTO and soil pore HTO result, and, b) Comparsion of soil nHTO and elemental zinc concentration in soil.

wells were sampled to the north and south of the affected area. Tritium in groundwater concentrations ranged from the minimum detection level of approx. $3 \mathrm{~Bq} \cdot \mathrm{L}^{-1}$, to $20 \mathrm{~Bq} \cdot \mathrm{L}^{-1}$.

Results (Table 1) do not provide a clear understanding of groundwater flow, but provide evidence that tritium is present at concentrations greater than would be expected from natural sources. WHO [4] recommends a maximum potable water tritium concentration of $1000 \mathrm{~Bq} \cdot \mathrm{L}^{-1}$, the guideline level being 50 times higher than the tritium maximum concentration level observed in groundwater monitoring wells sampled for this assessment.

Due to the highly localised, and limited quantity of contaminated soil that exceeded the more restrictive residential screening level of $8.5 \mathrm{~Bq} \cdot \mathrm{g}^{-1}$, it is considered that remediation of the subject area was not justified. The results of this study, and the 2003 survey, indicate that natural attenuation and dilution of the contaminant has occurred, and will continue to occur if the contamination source has been adequately controlled. The nature, extent and magnitude of tritium contamination suggest that there is no occupational risk to workers participating in normal duties in, or in proximity to, the facility and surrounds, or residential occupants of the site should the land use application change. 


\section{References}

[1] NCRP Report No. 146, National Council on Radiation Protection and Measurements, Bethesda, USA (2004).

[2] S.D. Castellano and R.P. Dick, Health Physics 65, 539-540 (1993).

[3] A. Gudelis, L. Juodis, M. Konstantinova, V. Remeikis, D. Baltrunas and D. Butkus, in LSC 2005, Advances in Liquid Scintillation Spectrometry International Liquid Scintillation Conference, Katowice, Poland 1996, edited by S. Chalupnik, F. Schonhofer and J. Noakes (Radiocarbon, The University of Arizona. Arizona 1996), p 331-341.

[4] WHO Guidelines for drinking-water quality, $1^{\text {st }}$ Addendum to $3^{\text {rd }}$ Edition. World Health Organisation, Geneva (2006). 
